\title{
PERSEPSI MASYARAKAT DESA BOKAK SEBUMBUN TERHADAP KEBERADAAN TAMAN KEANEKARAGAMAN HAYATI DI KECAMATAN SEKADAU HILIR KABUPATEN SEKADAU
}

\author{
(Community Perception Of The Bokak Sebumbun Village On The Exsistence Of Park \\ Biodiversity In Sekadau Hilir District Sakadau District)
}

\author{
Murniatun, Sofyan zainal, Idham \\ Fakultas Kehutanan Unifersitas Tanjungpura Jl, Daya nasional, Pontianak 78124 \\ E-mail : tymurniatun@gmail.com
}

\begin{abstract}
Indonesia is a country that has a very diverse wealt in the from of the beuty of flora and fauna ecosystems and natural phenomena. Given the importance of forests to people's lives both directly and indirectly, forest esources must be managed properly. One of these is natural resources the biodiversity park. The biodersity park is a reserve area of biological natural resource of local outside the forest area that has ex-situ and in-situ conservation, especially for plants that are pollinated or the locator is assistend bay animals with the composition and structure of vegetation that can suport the pollinator and scatter conservation seeds, there for the maintenance in biodiversity park. Therefore this study aims to examine the comunity perceptions of Bokak Sebumbun Village on the exsistence of he biodiversity park in Sekadau Hilir Subdistrict and to analize he relationship of age, knowlage and cosmopolitan factor from the perception of the Bokak Sebumbun Village to the exstence of biodiversity Parks. This study used an interview technique research method for 84 respondents to the head of the family in Bokak Sembumbun Village. Examples of respondent were conducted using purposive sampling technique. Data analysis using descriptive and inferential data analysis from the Kendall Tau correlation. The results show that people perceptions Bokak Sebumbun Village of existence biodiversity parks tend to be natural, because people basically realize that they depend on the surrounding biodiversity park. However, the comunity does not understand how to manage sustainably so that the benefits are sustainable.
\end{abstract}

Keywords: Perception, Bokak Sebumbun, Biodiversity Park.

\section{PENDAHULUAN}

Indonesia adalah suatu negara yang mempunyai kekayaan yang sangat beranekaragam, berupa keindahan flora dan fauna serta ekosistem maupun fenomena alam. Mengingat pentingnya hutan bagi kehidupan masyarakat baik langsung maupun tidak langsung maka sumberdaya hutan harus dikelola dengan baik. Salah satu sumberdaya alam tersebut adalah taman keanekaragaman hayati.
Taman Keanekaragaman Hayati adalah suatu kawasan cadangan sumberdaya alam hayati berupa lokal di luar kawasan hutan yang mempunyai konservasi ex-situ dan in-situ, dengan khususnya bagi tumbuhan yang penyerbukanya atau pemencaranya di bantu oleh satwa. Komposisi dan struktur vegetasi yang dapat mendukung kelestarian satwa penyerbuk dan pemencar biji, maka dari itu dalam pemeliharaan dan pada Taman Keanekaragaman Hayati harus di 
lakukan dengan bijak sana untuk menjamin keseimbangan dan persediaan dengan meningkatkan kualitas Keanekaragaman Hayati

Penelitian persepsi masyarakat terhadap keberadaan taman tersebut perlu dilakukan, agar mendapat informasi-informasi gambaran titik pengembangan objek wisata dan untuk memudahkan pengembangan atau memberikan daya tarik untuk antisipasi arah bagi pihak yang berwenang dalam menentukan langkah-langkah yang dianggap tepat, untuk menutupi setiap kelemahan-kelemahan terhadap aspekaspek pada objek wisata didalam rangka pengolahan maupun pembangunan di masa yang akan datang.

Wade dan travis (2007) mengemukaan bahwa persepsi merupakan sekumpulan tindakan mental yang mengatur implus-implus sensorik menjadi satu pola bermakna. Indra penglihatan kita menghasilkan menghasilkan gambar-gambar dua dimensi. Kemampuan paling mendasar pada manusia dan kemampuan persepsi adalah suatu yang sifatnya bawaan dan berkembang pada masa yang sangat dini. Kebanyakan kemampuan persepsi bersifat bawaan, pengalaman, juga memainkan peranan penting. Pengertian persepsi menurut Baron dan Byrne (2004) yaitu suatu proses memilih mengorganisir, dan menginterprestasi informasi dikumpulkan oleh pengertian seseorang dengan maksud untuk memahami dunia sekitar.

Berdasarkan masalah yang dikemukakan, (1) bagaimana Persepsi
Desa Bokak Sebmbun Terhadap Keberadaan Taman Keanekaragaman Hayati Di Kecamatan Sekadau Hilir, (2) apakah ada hubungan umur, pengetahuan, dan kosmopolitan terhadap persepsi masyarakat Desa Bokak Sebumbun Terhadap Keberadaan Taman Keanekaragaman Hayati di Kecamatan Sekadau Hilir. Penelitian ini bertujuan untuk mengkaji persepsi masyarakat Desa Bokak Sebumbun Terhadap Taman Keanekaragaman Hayati dan Menganalisis hubungan dari masing-masing faktor: umur, pengetahuan, dan kosmopolitan dari Peresepsi Masyarakat Desa Bokak Sebumbun Terhadap Keberadaan Taman Keanekaragaman Hayati.

\section{METODE PENELITIAN}

Penelitian dilakukan di Desa Bokak Sebumbun Kecamatan Sekadau Hilir. Kegiatan penelitian ini dilaksanakan pada tanggal 12 Oktober 2018 - 26 Oktober 2018. Penentuan lokasi penelitian ini secara sengaja (purposive) berdasarkan pada pengamatan penelitian. Penelitian ini dilaksanakan pada Desa Bokak Sebumbun yang dipilih dua dusun yaitu Dusun Bokak Dan Dusun Entada.

Metode pengumpulan data dilakukan menggunakan teknik wawancara yang langsung dibantu dengan menggunakan alat kuisioner berupa daftar pertanyaan yang diberikan kepada responden. Objek penelitian ini adalah Taman Keanekaragaman Hayti Kabupaten Sekadau yang terdapat di Desa Bokak Sebumbun. Pengambilan sampel menggukan teknik purposive 
sampling yaitu pengambilan sampel dengan menekankan pertimbangan pada ksrakteristik tertentu dari objek penelitian (Sugiono, 2013). Menentukan akan besarnya ukuran sampel menggunakan rumus Slovin (Kusmayadi dan Enda, dalam Dimas (2010).

$$
n=\frac{\mathrm{N}}{1+\mathrm{Ne}^{2}}
$$

Keterangan :

$n=$ ukuran/jumlah sampel

$N=$ ukuran/jumlah populasi

$e=$ batas kesalahan/error (persen kelonggaran)

Kriteria masyarakat yang akan dijadikan responden secara purposive sampling adalah (1). Kepala keluarga yang berada/berdomisili di Desa Bokak Sebumbun, (2). Berdomisili di dusun setempat minimal 5 tahun, (3). Sehat jasmani dan rohani, (4). Usia minimal 17 tahun dan sudah menikah dan (5). Bisa membaca dan menulis.

Berdasarkan perhitungan rumus Slovin tersebut mempunyai total 84 responden. Total 84 responden tersebut di luar sampel untuk uji validitas dan uji reliabilias sebanyak 10 responden. Responden yang telah diambil di Desa Bokak Sebumbun. Guna lebih jelas dapat dilihat pada Tabel 1 .

Tabel 1. Daftar Jumlah Populasi Responden Pada Penelitian (List of Population Respondent The Research)

\begin{tabular}{lcccc}
\hline \multicolumn{1}{c}{ Lokasi/Dusun } & $\begin{array}{c}\text { Jumlah } \\
\text { Populasi (KK) }\end{array}$ & Laki-Laki & Perempuan & Jumlah Sampel \\
\hline Sungai Raya & 129 & 236 & 197 & 20 \\
Entada & 78 & 175 & 130 & 12 \\
Kampung Ensibau & 61 & 106 & 98 & 10 \\
Bokak & 226 & 457 & 383 & 42 \\
\hline \multicolumn{1}{c}{ Jumlah } & 535 & 974 & 808 & 84 \\
\hline
\end{tabular}

Sumber : Profil Desa Bokak Sebumbun Tahun 2018 (Bokak Sebumbun Village Profil 2018)

Data yang diperoleh meliputi : (1).

Data primer adalah data yang diperoleh untuk peneliti meliputi persepsi masyarakat terhadap keberadaan taman keanekaragaman hayati di Desa Bokak sebumbun Kecamatan Sekadau Hilir, dengan tingkat umur, tingkat pengetahuan dan tingkat kosmopolitan. (2). Data skunder yaitu sumber data penelitian yang diperoleh melalui media perantara atau tidak langsung yang berupa buku, catatan, bukti yang telah ada, atau arsip yang dipublikasikan maupun tidak dipublikasiakan secara umum.

\section{HASIL DAN PEMBAHASAN}

\section{Persepsi Masyarakat Desa Bokak Sebumbun Terhadap Keberadaan Taman Keanekaragaman Hayati}

Hasil penelitian yang telah dilakukan di Desa Bokak Sebumbun, dapat diketahui persepsi masyarakat Desa Bokak Sebumbun terhadap kebaradaan taman keanekaragaman hayati Kecamatan Sekadau Hilir Kabupaten Sekadau dengan beberapa 
faktor individu yang mempengaruhi pengetahuan dan tingkat kosmopolitan, seperti tingkat umur, tingkat dapat dilihat pada Tabel 2. Tabel 2. Frekuensi Responden Berdasarkan Persepsi Masyarakat Di Desa Bokak Sebumbun Terhadap Keberadaan Taman Keanekaragaman Hayati (Respondents frequency By communities Perception Bokak Sebumbun Village To The Exitence Of Biodiversity Park)

\begin{tabular}{cccc}
\hline No & Persepsi & Frekuensi & Presentase \% \\
\hline 1 & Positif & 19 & 22,61 \\
2 & Netral & 60 & 71,42 \\
3 & Negatif & 5 & 5,95 \\
\hline \multicolumn{2}{r}{ Jumlah } & 84 & 100 \\
\hline
\end{tabular}

Berdasarkan hasil pengamatan dalam penelitian, sebagaimana telah ditunjukan pada Tabel 2. Tingkat persepsi masyarakat terhadap keberadaan taman keanekaragaman hayati yaitu 84 responden, sebanyak 19 responden $22,61 \%$ memiliki tingkat persepsi tinggi, 60 responden 71,42\% memiliki tingkat persepsi netral, dan 4 responden 5,95 \% memiliki tingkat persepsi Negatif terhadap keberadaan taman keanekaragaman hayati Kecamatan Sekadau Hilir.

Hasil uji stastistik uji deskriptif (uji chi-squer) diperoleh chi-squer (r) hitung pada taraf kepercayaan $95 \%$ sebesar 58,35 dan nilai chi-squer tabel 5,99 $\mathrm{R}$ hiting, > r tabel), hasil uji statistik deskriptif (terlampir). Berdasarkan hasil uji statistik deskriptif dapat disimpulkan bahwa terdapat perbedaan signifikan frekuensi persepsi masyarakat terhadap taman keanekaragaman hayati di Desa Bokak Sebumbun Kecamatan Sekadau Hilir (Ha diterima dan Ho ditolak).

Hasil olahan data primer sebagaimana diuraikan pada Tabel 2 . Uji statistik deskriptif dapat diinterprestasikan bahwa dari 84 responden penelitian sebagai besar
$(71,42 \%)$ cenderung memiliki persepsi netral terhadap keberadaan taman keanekaragaman hayati di Desa Bokak Sebumbun. Persepsi masyarakat cenderung pada netral terhadap pada taman disebabkan pada dasarnya masyarakat menyadari bahwa mereka bergantung pada sumber hayati hutan. Masyarakat belum memahami kalau sumber daya tersebut perlu dikelola secara lestari agar manfaatnya bisa diperoleh secara berkelanjutan.

Persepsi netral terhadap keberadaan taman keanekaragaman hayati di Desa Bokak Sebumbun penilaian masyarakat terhadap manfaat taman keanekaragaman hayati lebih besar di bandingkan manfaat lainaya. Manfaat lainnya dari taman keanekaragaman hayati tersebut berupa ekologi, sosial, budaya dan politik. Berdasarkan segi sosial dan politik masyarakat tidak mengetahui secara pasti kebijakan pemerintah dalam membangun atau pengelolaan taman tersebut, terutama masa yang akan datang. Nilawati, (2013) menjelaskan apabila persepsi seseorang positif terhadap suatu hal, maka pengambilan suatu hal pun akan 
selarasdengan persepsi tersebut ataupun sebaliknya.

Masyarakat yang mempunyai persepsi netral ini mau dan memperhatikan setiap informasi tentang keberadaan taman keanekaragaman hayati di Desa Bokak Sebumbun. Masyarakat tidak merespon atau memberi jawaban apabila ditanya mengenai peran serta masyarakat dalam pengelolaan atau pelestarian taman keanekaragaman hayati sekitar. Masyarakat juga tidak mempunyai inisiatif mengajak orang lain untuk

Tabel 3. Hasil Uji Statistik Korelasi Kendall Tau Hubungan Variabel Terikat Dan Variabel Bebas (Statisticcal Test Results The Kendall Tau Correlation Between Dependent Variable And Independent Variables)

\begin{tabular}{|c|c|c|c|c|c|}
\hline No & Variabel & $\mathbf{N}$ & $\begin{array}{c}\text { Persepsi } \\
\text { Korelation } \\
\text { Coeffisient }\end{array}$ & $\begin{array}{c}\text { Sig } \\
\text { (2-tailed) }\end{array}$ & Keterangan \\
\hline 1 & Umur & 84 & $-0,079$ & 0,350 & Tidak signifikan \\
\hline 2 & Pengetahua & 84 & 0,343 & 0,000 & Signifikan \\
\hline 3 & Kosmopolitan & 84 & $-0,368$ & 0,003 & Signifikan \\
\hline
\end{tabular}

a. Hubungan Persepsi Masyarakat

Dengan Tingkat Umur

Hasil uji statistik korelasi Kendal Tau antara persepsi masyarakat terhadap keberadaan taman keanekaragaman hayati di Desa Bokak Sebumbun dengan tingkat umur diperoleh dengan nilai Sig. (2-tailed) ,305 lebih besar dari taraf signifikan 5 $\%$ atau nilai Sig 0,305 > 0,05 dengan nilai koofisien korelasi negatif sebesar 0,079. Hasil menunjukan bahwa tidak ada hubungan signifikan antar persepasi masyarakat terhadap taman keanekaragaman hayati di Desa Bokak Sebumbun dengan tingkat umur masyarakat (H0 diterima dan $\mathrm{H} 0$ menjaga taman keanekaragaman hayati agar berfungsi sebagai semestinya. Masyarakat ini tidak mau bertanggung jawab atau memberikan segala sesuatu dengan segala resiko dimasa yang akan datang.

\section{Hubungan Variabel Terikat Dan} Variabel Bebas

Hasil pada uji statistik korelasi Kendall Tau untuk mengetahui pada hubungan satu variabel terikat dan tiga variabel bebas seperti disajikan pada Tabel 3. 
Sebumbun 71,42 \% cenderung netral. Masyarakat dengan tingkat usia dewasa memiliki persepsi sedang atau netral terhadap taman keanekaragaman hayati, hal ini disebabkan karena tidak membatasi usia seseorang untuk mengetahui segala sesuatu bagi kehidupan. Sejalan dengan pendapat harsojo (1990) dalam kadhapi (2015) bahwa faktor umur tidak menentukan kebebasan seseorang dalam bertindak dan memiliki peran penting dalam diri seseorang manusia serta tidak lagi menentukan apakah seseorang itu memiliki pengetahuan yang bantak atau tidak.

b. Hubungan Persepsi Masyarakat Dengan Tingkat Pengetahun

Hasil uji statistik korelasi Kendall Tau antara persepsi masyarakat terhadap keberadaan taman keanekaragaman hayati di Desa Bokak Sebumbun dengan tingkat pengetahuan masyarakat di peroleh nilai Sig. (2tailed) 0,000 lebih kecil dari taraf signifikan $5 \%$ atau nilai Sig $<0,05$ dengan kooefisien korelasi positif sebesar 0,343. Hal ini menunjukan bahwa terdapat hubungan signifikan antara persepsi masyarakat terhadap keberadaan taman keanekaragaman hayati di Desa Bokak Sebumbun dengan tingkat pengetahuan masyarakat (Ha diterima dan Ho ditolak) persepsi masyarakat didukung oleh pengetahuan masyarakat tentang lingkungan dan pentingnya taman dalam kehidupan masyarakat seperti dalam peningkatan taraf ekonomi baik dari diri sendiri maupun keluarga (Nurhayati, 2018).
Nilai koofisien korelasi positif menunjukan semakin semakin positif atau tinggi tingkat pengetahuan masyarakat maka persepsi masyarakat terhadap keberadaan taman keanekaragaman hayati di Desa Bokak Sebumbun akan cenderung netral atau positif.

Berdasarkan hasil pengamatan diketahui bahwa tingkat pengetahuan masyarakat terhadap keberadaan taman keanekaragaman hayati di Desa Bokak Sebumbun sebagai besar 67,53\% cenderung sedang. Sedangkan persepsi terhadap keberadaan taman keanekaragaman hayati di Desa Bokak Sebumbun sebagian besar 71,42\% cenderung netral. Pengetahuan masyarakat terhadap taman keanekargaman hayati masih kurang, sehingga menilai atau pendapat masyarakat cenderung netral. Sejalan dengan Nonlohy (2014) dalam penelitian mengatakan bahwa persepsi masyarakat sangat dipengaruhi oleh pengetahuan masyarakat pengetahuan mengenai keberadaan sangat penting karena merupakan gambaran mengenai popularitas lokasi masyarakat yang juga menunjukan adanya keterkaitan masyarakat umumnya harus diberikan pengetahuan penyuluhan atau pelatihan terhadap pengelolaan kawasan taman terhadap pelestarian tersebut.

c. Hubungan Persepsi Masyarakat

Terhadap Tingkat Kosmopolitan

Hasil uji statistik korelasi Kendall Tau antara persepsi masyarakat terhadap keberadaan taman keanekaragaman hayati di Desa Bokak 
Sebumbun dengan tingkat kosmopolitan masyarakat diperoleh dengan nilai Sig.(2-tailed) 0,003 lebih kecil dari taraf signifikan $5 \%$ atau nilai sig 0,003 < 0,05 dengan koofisien korelasi negatif sebesar 0,368, hal ini menunjukan bahwa terdapat hubungan yang signifikan antara persepsi masyarakat terhadap keberadaan taman keanekaragaman hayati di Desa Bokak Sebumbun dengan tingkat kosmopolitan masyarakat (Ha diterima dan Ho ditolak). Sejalan dengan penelitian Nutriwani (2017) menjelaskan bahwa tingkat kosmopolitan masyarakat berpengaruh positif terhadap persepsi masyarakat. Nilai koofisien korelasi negatif menunjukan bahwa semakin negatif atau rendah tingkat kosmopolitan masyarakat, maka persepsi masyarakat di Desa Bokak Sebumbun terhdap keberadaan taman keanekargaman hayati akan cenderung negatif.

Berdaarkan hasil pengetahuan diketahui bahwa tingkat kosmopolitan masyarakat terhdap keberadaan taman keanekaragaman hayati di Desa Boakak Sebumbun sebesar 48,80\% cenderung sedang, sedangkan persepsi masyarakat Desa Bokak Sebumbun terhadap keberadaan taman keanekaragaman hayati di Desa Boakak Sebumbun 71,42 $5 \%$ cenderung netral. Persepsi masyarakat yang netral disebabkan karena masyarakat tidak mau mencari atau memiliki keterbukaan dalam menerima informasi-informasi yang ada mengenai taman keanekargaman hayati di Desa Bokak Sebumbun. Kurniawan
(2008) menjelaskan bahwa tingkat kosmopolitan adalah kemauan, keterbukaan atau kemauan seseorang untuk melakukan perjalanan keluar desa atau komunitasnya, frekuensi aktifitas seseorang menghadiri pertemuan resmi atau tidak resmi, akses pada bendabenda yang memungkinkan responden yang dapat berinteraksi pada orangorang yang berada diluar komunitasnya seperti, kepemilikan telepon seluler, kendaraan motor, televisi, dan sumber informasi atau majalah.

\section{KESIMPULAN}

1. Persepsi masyarakat terhadap keberadaan taman keanekaragaman hayati di Desa Boakak Sebumbun Di Kecamatan Sekadau Hilir Kabupaten Sekadau 71,42\% cenderung netral.

2. Tedapat hubungan yang signifikan atara persepsi masyarakat terhadap keberadaan taman keanekaragaman hayati di Desa Bokak Sebumbun dengan tingkat umur, pengetahuan dan kosmopolitan, antara lain :

a. Hasil persepsi masyarakat terhadap keberadaan taman keanekargaman hayati di Desa Bokak Sebumbun dengan tingkat umur memperoleh nilai koefisien korelasi -0,079, disimpulkan bahwa tidak terdapat hubungan yang signifikan antara umur dan persepsi masyarakat.

b. Hasil persepsi masyarakat terhadap keberadaan taman keanekaragaman hayati di Desa Bokak Sebumbun dengan tingkat pengetahuan diperoleh nilai koefisien korelasi positif sebesar 
0,343, disimpulkan terdapat hubungan yang signifikan antara persepsi dan pengetahuan tersebut.

c. Hasil persepsi masyarakat terhadap keberadaan taman keanekaragaman hayati di Desa Bokak Sebumbun dengan tingkat kosmopolitan memperoleh nilai koefiesien korelasi 0,368, disimpulkan bahwa terdapat hubungan yang signifikan antara persepsi dan kosmopolitan tersebut.

\section{SARAN}

1. Mengingat persepsi masyarakat berhubungan signifikan terhadap tingkat umur, tingkat pengetahuan, dan tingkat kosmopolitan, maka tiga variabel tersebut harus dikelola dengan intansiintansi terikat.

2. Peningkatan variabel pendidikan bisa dilakukan dengan upaya memberi pengetahuan harus dilibatkan dalam pengelolaan taman keanekargaman hayati.

3. Untuk mengembangkan taman keanekaragaman hayati di Desa Bokak Sebumbun perlu penelitian lanjutan yang berhubungan potensi dan strategi pengembangan taman

keanekaragaman hayati.

\section{UCAPAN TERIMAKASIH}

Penulis mengucapkan terimakasih yang sebesar-besarnya kepada pengelola taman keanekaragaman hayati Di Desa Bokak Sebumbun Kecamatan Sekadau Hilir, Bapak Kepala Desa dan masyarakat Desa Bokak Sebumbun yang telah membantu penelitian yang sudah terlaksana. Akhir kata dalam segala kerendahan hati penulis berharap semoga jurnal ini dapat bermanfaat bagi banyak pihak dan digunakan semestinya.

\section{DAFTAR PUSTAKA}

Baron RA, Byrne D. 2004. Psikologi sosial Jilid 1. Edisi kesepuluh. Jakarta (ID): Pratama Gelora Aksara.

Dhimas W, Asbar L. 2010. Kajian Pengelolaan Hutan Mangrove di Kawasan Konservasi Desa Mambarungan Kota Tarakan Kalimantan Timur. Fakultas Perikanan dan Ilmu Kelautan Universitas Borneo.

Heryatna D, Sofyan Z, Harnani H. 2015. Persepsi Masyarakat Terhadap Keberadaan Hutan Keasyarakatan Di Desa Meragun Kecamatan Nanga Taman Kabupaten Sekadau. [Jurnal] Hutan Lestari Vol 4 No 1.

Khadapi M, Gusti H, Sofyan Z. 2015. Persepsi Masyarakat Desa Sungai Awan Kanan Terhadap Keberadaan Hutan Mangrove Di Kawasan Pantai Air Mata Permai Kabupaten Ketapang. [Jurnal] Hutan Lestari.

Kurniawan, E. 2008. Faktor-Faktor Yang mempengaruhi parsitipasi masyarakat pada gerakan nasional.[Skipsi]. Fakultas Pertanian Institut Pertanian Bogor. From https://core.acuk/download/pdf/32 348993.pdf. Diakses17 Agustus 2018.

Nilawati. 2013. Hubungan Antara Persepsi dengan Sikap Orangtua Terhadap PaudKhairunnisa 
Seberang Padang Kecamatan Padang Selatan Kota Padang. Jurnal Spektrum Pls.

Nanlohy H, Aziz N.B, Ambaryanto, Sahala H. 2014. Analisis Persepsi Masyarakat

Nurhayati, Amar M, Nur A. 2018. Persepsi dan Sikap Masyarakat Terhadap Pengembangan Taman Keanekaragaman Hayati. Fakultas Kehutanan dan Ilmu Lingkungan Universitas Halu Oleo.

Nutriwani R, Bachrun N, Joko N. 2017. Sikap Masyarakat Dusun Pasir Laut Terhadap Keberadaan
Hutan Mangrove Di Dusun Pasir Laut Kecamatan Mempawah Hilir Kabupaten Mempawah.

Sugiono. (2013). Metode Penelitian Pendidikan Bandung: Afabeta, Dhimas Wiharyanto dan Asbar Laga, 2010. Kajian Pengelolaan Hutan Mangrove Di Kawasan Konservasi Desa Mambarungan Kota Tarakan Kalimantan Timur, Fakultas Perikanan Dan Ilmu Kehutanan Univ Borneo. Tarakan Jurnal.

Wade C, dan Tavris C. 2007. Psikologi jilid 1. Edisi kesembilan. Jakarta (ID): Pratama Gelora Aksara. 